\title{
Motivating Pro-Sustainable Behavior: The Potential of Green Events-A Case-Study from the Munich Streetlife Festival
}

\author{
Christina Tölkes * and Elias Butzmann * \\ Department of Tourism, Munich University of Applied Sciences, 80636 München, Germany \\ * Correspondence: christina.toelkes@hm.edu (C.T.); elias.butzmann@hm.edu (E.B.); \\ Tel.: +49-89-1265-2156 (C.T.); +49-89-1265-2157 (E.B.)
}

Received: 17 August 2018; Accepted: 11 October 2018; Published: 17 October 2018

\begin{abstract}
Green events are staged to encourage visitors to adopt more sustainable lifestyles. The Munich Streetlife Festival (SLF) has such a sustainability focus reflected in an education program that aims to reach out to both sustainability-minded visitors and broader audiences. Therefore, this study examined the learning effects of the SLF's education program regarding different visitor segments. We employed the transtheoretical model (TTM) and the theory of planned behavior (TPB), to relate the learning outcomes to the visitors' positioning in the stages of change model and visitor attitudes, subjective norms, and constraints. We conducted a visitor survey during the SLF in May 2015 and employed structural equation modelling to analyze the data. The motivational variable "learning about environmental protection" is positively correlated with pro-sustainable behaviors, whilst the variable "enjoying the event" shows a negative correlation. Our findings indicated that this event's sustainability communication mainly appealed to sustainability-minded visitors in the action stage. Conscious visitors showed higher learning effects than visitors in the pre-contemplation stage, which was in line with the TTM's propositions. This study enhanced our theoretical understanding of visitor behavioral change and supported green event managers in the development of target-group specific and more effective sustainability communications.
\end{abstract}

Keywords: events; sustainable consumption; consumer behavior; sustainability education; sustainability communication; structural equation modelling; sustainable tourism; social psychology

\section{Introduction}

The event sector is a fast-growing phenomenon that links tourism, leisure, and business [1,2]. While events are primarily staged for financial gain, they have also begun to adopt the role of more broadly addressing societal and social issues, such as sustainability [3-5]. These so-called green events represent a new type of event and are usually financed and organized by local authorities to motivate visitors and the local community towards more sustainable behaviors [6]. Green events are defined as a type of event characterized by the integration of sustainability guidelines into their planning, organization, and management processes. Although the title alludes to a focus on environmental-friendliness, green events address sustainability issues in a holistic way adopting an economic, social-cultural, and environmental perspective on sustainability $[4,6]$. Practically, the term green event and sustainability-focused event are interchangeably used [6,7]. Reference [7] defines the key elements of this event type as being the adoption of sustainability principles in the event's management, the aim to reduce potential negative effects resulting from its staging, the consideration of financial objectives, and the intention to inform event attendees of sustainability issues and educate and motivate them toward sustainable behavioral change (e.g., Reference [6]). Green festivals show 
special sustainability features that are evident in the themes that run through the events' entertainment and education program, its catering, the products and services provided, its decorations and designs, or the transportation services arranged for the event. These attributes are meant to reduce potential environmental damages associated with the staging of events (e.g., References [8-10]), but also find ways of differentiation and image-building in relation to other festivals [2,11].

In most cases, local authorities organize green events with the intention to motivate the general public to more sustainable behaviors [6].

Sustainability communication aims to bring the principles of sustainable development into social discourse, and to shape a critical awareness among the public towards the (negative) impacts of a human-environment relationship [12]. Green events provide such information in an attempt to educate visitors on sustainability and behavioral change [7]. More specifically, the event's education program provides information about environmental protection and more sustainable lifestyles, the use of environmental-friendly forms of transportation, or healthy food $[4,13]$. While sustainability-focused events are gaining popularity, they attract visitors from local communities, as well as tourists [6], and have the potential to attract a variety of different consumer segments. Green seekers are one important segment of potential event visitors [14]. These visitors show their concern for environmental issues, tend to be positively minded towards measures of environmental protection, and are interested in committing themselves proactively to environmentally-friendly practices [11,14]. Therefore, this visitor segment is particularly motivated to attend such green events [15] and to spend around one third more on green food on a festival [14]. However, Reference [6] shows that green events do not only attract sustainability-minded visitors and refers to the important need for marketing to attract wider audiences. To create successful marketing measures, it is important that event organizers know what motivated their visitors to come to a festival [16].

This study aims to investigate the learning effects of a green event by studying the case of the Munich Streetlife Festival's education for sustainability program on different visitor segments. This is the first study which draws on the transtheoretical model of change (TTM) [17] and the theory of planned behavior (TPB) [18] to explain the learning outcomes of green events on different visitor segments. More precisely, it investigates attitudes, a subjective norm, and constraints upon SLF visitors regarding pro-sustainability engagements by means of the theory of planned behavior [18]. Furthermore, it examines respondents' positioning in the transtheoretical model of change [17] to draw conclusions based upon the learning outcomes. While this article sets out to contribute to a more comprehensive theoretical understanding of sustainability communication on events and its effects on consumer behavior, this investigation also seeks to develop implications for event practitioners. On the one hand, the TPB conveys an in-depth understanding of the different beliefs and motivations of event visitors, and thereby increases our knowledge of the drivers and barriers of behavioral change. This, in turn, will inform marketers on how to develop target-group specific messages that appeal to such factors [19]. On the other hand, the TTM provides a more dynamic approach to behavioral change $[6,20,21]$, which complements the TPB's perspective. Given that empirical evidence of "stage-matched" inventions is weak in comparison to non-matched communications [21], we seek to contribute to this knowledge gap by our research.

\section{Literature Review}

In doing so, this article seeks to respond to a series of knowledge in the field. Despite the growing importance of green events for tourism and as a vehicle for education for sustainability, their investigation has received little attention in tourism research [2,6,22]. Reference [7] critically comments that visitors have their own attitudes and behaviors in terms of sustainability, which may not necessarily correspond to the event management's sustainability goals. Furthermore, pro-sustainable attitudes do not always translate into action [23], which is a global problem that also applies to events [24]. For example, Reference [25] indicated that green consumers' intention to buy organic food is positively influenced by tie strength and green expertise among senders and receivers. Some studies 
mention the inspirational function of (green) events on attitudes [7,24]. However, little is understood about how green events and their related sustainability communications can affect on behavioral change $[2,6,22]$. Furthermore, there remain knowledge gaps as to how these understandings can be grounded in theory $[2,6,26]$.

The TTM has been abundantly used to explain change of health behavior (e.g., Reference [27]) and to gain understanding of engagement with sports and physical exercise (e.g., Reference [24]). In contrast, the TTM has scarcely been used to study tourism in general, or more particularly with regard to the investigation of sustainability-focused events [6]. The authors of Reference [6], in one of the few studies on green events, show that the TTM is a suitable framework for explaining the effects of such events on visitor behavioral change. They encourage the use of the TTM for further research in the context of sustainability-focused events. Given that Reference [6] refers to the need to use the TTM for sustainability-focused events staged in different countries (other than Australia), and which are not sustainability-themed, we respond to this knowledge gap. More specifically, the TTM has not yet been used to examine the effects of sustainability communication as a form of persuasive intervention on green event visitor behaviors on different visitor segments [21]. While we aim to respond to this knowledge, in addition, we seek to contribute to theory development, by combining the TTM with the TPB [18] as a contribution to extant research in terms of the effects of green events on responsible behavior. The explanatory power of the TPB has been widely employed to predict pro-environmental decisions in hospitality and tourism research. For example, the theory has been used to explain leisure activities [17,28], green hotel choices (e.g., Reference [29]), destination choice (e.g., Reference [30]), or sustainable behaviors in more specific tourism segments, such as heritage tourism [31] or wine tourism [32]. In terms of events, the TPB has been used to explain visitors' intentions to revisit a traditional folk event [31]. Reference [33] increases the predictive power of the TPB by relating the concept of lifestyles. Developing a behavioral model for attendees of food events, the authors show that different visitor segments show different behaviors. The TPB has not yet been employed to explain the effects of green events on visitor motivation to adopt more sustainable lifestyles and has not yet been combined with the TTM to do so. Therefore, in the next section, firstly the basics of the TTM and TPB are presented, which form the basis of the conceptual framework for this study.

\section{Theoretical and Conceptual Framework}

\subsection{The Transtheoretical Model of Change}

The transtheoretical model of change (TTM) [17] describes behavioral change as a sequential model of five stages. These five stages are: pre-contemplation, contemplation, preparation, action, and maintenance of behavior [21] (p. 132). During the first stage-the pre-contemplation stage-individuals do not feel a need to make changes in their lives as they are simply not conscious of any problem. During the contemplation stage, however, people become aware of issues that require behavioral change and begin to balance the costs and benefits of engaging in future actions, such as pro-environmental behaviors. During this stage, individuals are open to persuasive messages that support their motivation to take pro-sustainable actions $[6,20,21]$. While individuals start to take the first steps towards behavioral change during the preparation stage, in the action and maintenance stages they behave pro-environmentally but need help and backing to continue to do so [6].

The TTM accounts for dynamic processes as people might move forwards and backwards during processes of behavioral change or even move between different stages $[6,27,28]$. The model also considers that people may succeed in making certain changes but stand still at other points, or even fall back into the pre-contemplation or contemplation stage. Therefore, the TTM considers different processes that support a person's progress towards the next stage of behavioral change [6,21]. While the stage of change model explains when certain changes in attitudes or behaviors take place, the integrated process model provides the reasons why these changes occur $[6,17]$. Since behavioral change can only be fully understood when its underlying attitudes, motivations, or emotions are 
analyzed and explained, the TTM also considers these dimensions. While the first three stages are conceptualized as the attitudinal dimensions of change, the other stages in the process refer to behavior more precisely [6,34]. The model considers external influences such as the provision of (persuasive) information and its influence on an individual's decision-making process [6].

\subsection{The Theory of Planned Behavior}

The theory of planned behavior (TPB) $[18,28]$ is an expectancy-value theory that consists of three major beliefs that influence behavioral intentions: behavioral beliefs, a subjective norm, and perceived behavioral control. The TPB is an extended version of the theory of reasoned action and relates to actions without volitional control $[18,35]$. Behavioral beliefs depict people's beliefs about the outcomes of their behavior and their evaluation of those outcomes. Consequently, individuals will prefer actions that are associated with positive consequences, while they tend to refrain from behaviors that produce undesirable outcomes. A second determinant of the TPB is a subjective norm, which refers to one's beliefs about whether certain reference groups support or reject one's potential actions. Importantly, these normative beliefs also indicate one's readiness to comply with such reference groups. A third determinant in this construct is a variable of perceived behavioral control, which refers to any constraint that might drive or impede an individual's performance of an action [18,35]. Reference [18] concludes that the extent of perceived behavioral control is positively influenced by one's beliefs about the resources and chances for a performance, while beliefs about anticipated obstacles have a negative effect. Accordingly, these behavioral beliefs, a subjective norm and a variable of perceived behavioral control influence our attitude towards behaving in a particular way.

\subsection{Conceptual Framework and Research Hypotheses}

Theories of persuasion and behavioral change consider that the audience adopts different (mental) states, which in turn, influence behavioral outcomes. These theoretical perspectives posit that interventions should target the recipient's particular state at the point at which they receive the message. The TTM and the TPB differ in terms of their understanding of how different beliefs influence behavior. On the one hand, the TPB represents a continuum model which adopts a more generalist approach by conceiving behavioral determinants as applicable to everyone. For communication measures to be effective, this means that messages should match recipients' current mental states. In contrast, the TTM proposes a dynamic model based on a series of temporally ordered mental states through which individuals move. This, in turn, means that the effectiveness of different influencing factors varies depending on the stages through which individuals pass [21].

This is the first study to draw on the TTM [17] and the TPB [18] to explain the learning outcomes of green events for different visitor segments. Since the TPB conveys an in-depth understanding of the different beliefs and motivations of event visitors and thereby increases our knowledge of the drivers and barriers of behavioral change, marketers will be informed of how to develop target-group specific messages that appeal to such factors [19]. Given that empirical evidence of "stage-matched" inventions is weak in comparison to non-matched communications [21], we seek to contribute to this knowledge gap through our research.

The conceptual framework presents the constructs of the theoretical framework (see Figure 1). The framework is composed of six independent variables and one main dependent variable. First, there are the motivational variables which are intended to differentiate sustainability-motivated visitors from those who were initially drawn for reasons other than sustainability. While the motive "environmental protection/charity projects" relates to event visitors motivated to visit the SLF for sustainability purposes, the other main motive, "to have fun/stroll/enjoy the food", describes those who have been motivated to come for the 'sake of events' (which does not necessarily involve pro-sustainability motives). The conceptual model also involves the additional constructs of the TPB as expressed by an attitude towards pro-environmental action, a subjective and moral norm, and constraints. The variable "attitude towards environmental behavior" relates to the first stages 
of the TTM (pre-contemplation, contemplation, preparation), whilst "pro-environmental action" represents the action and maintenance stage of the model. The dependent variable in this framework is represented by the learning effect regarding ecological behavior.

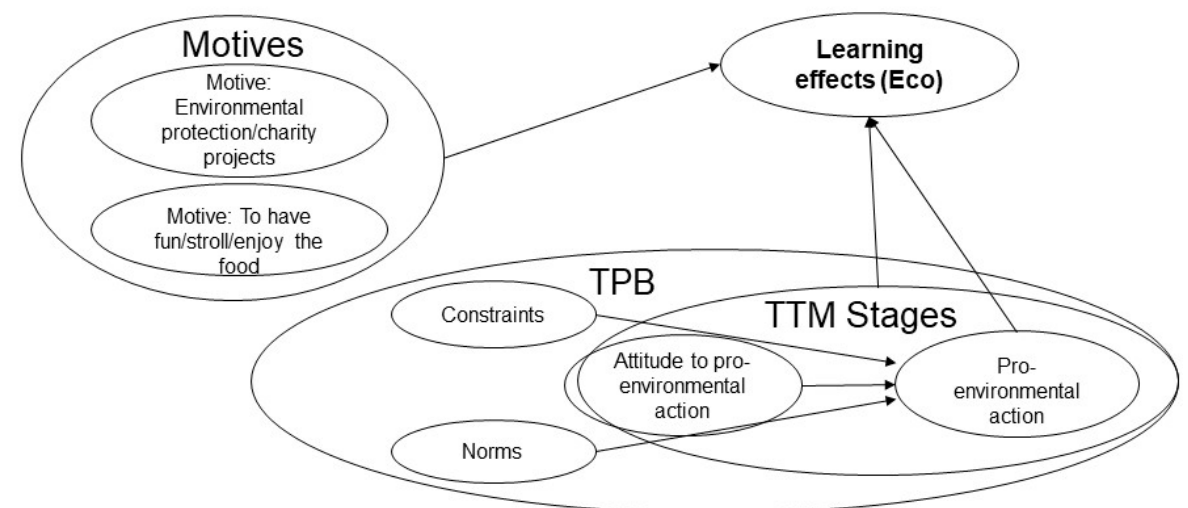

Figure 1. Conceptual framework.

This study uses a quantitative survey-based approach to investigate how visitors perceive the festival, to identify the learning results of the SLF's educational program for sustainability, and to understand visitor attitudes and behaviors towards sustainability. Based on the conceptual framework, the following major research hypotheses were formulated:

(1) Which factors determine the levels of visitor satisfaction and visitor expectations? How is the visitor profile characterized?

(2) How can the learning effects of the educational program for sustainability be defined, and do motives to visit the event influence learning effects?

Hypothesis 1 (H1). People's motive to get informed about environmental protection/charity projects has a significant positive influence on learning effects.

Hypothesis 2 (H2). People's motive to have fun/stroll around and relax has a significant negative influence on learning effects.

Hypothesis 3 (H3). People's awareness of constraints to act sustainable in their everyday life has a significant positive influence on learning effects.

(3) How do components of the TPB directly or indirectly affect learning effects?

Hypothesis 4 (H4). People's awareness of constraints to act sustainable in their everyday life has a significant negative influence on environmental behavior.

Hypothesis 5 (H5). A pro-environmental attitude significantly positively influences environmental behavior.

Hypothesis 6 (H6). Moral obligation positively influences environmental behavior.

Hypothesis 7 (H7). Social norms positively influence environmental behavior.

(4) How does belonging to different stages of the TTM affect learning effects?

Hypothesis 8 (H8). Environmental behavior significantly influences learning effects.

Hypothesis 9 (H9). People's belonging to a certain stage of the TTM significantly influences learning effects. 
In the following section, we will present more in detail how these questions and constructs were operationalized in the survey instrument.

\section{Materials and Methods}

\subsection{Study Context}

The focus of this study was the Munich Streetlife Festival (SLF), in the city center of Munich, which is a sustainability-focused event and is one of the leading festivals of its kind in Europe. The festival was founded in the year 2000 in response to the Europe-wide Car Free Day. The event was initiated to make the public aware of alternative forms of mobility and to use the public space in a more innovative way; for example, for green events. The SLF has been steadily growing in popularity, with visitors from nearby or outside the city, and attracts between 250,000 and 300,000 visitors to each event. It is a two-day festival that takes place twice a year, in spring and autumn, and stretches over $2.5 \mathrm{~km}$ of Ludwig Street and Leopold Street, two of the largest streets in Munich, and one of its major traffic junctions. The Green City initiative turns these streets into a pedestrianized zone where more than 120 exhibitors present their initiatives, products, services, and catering, accompanied by a broad entertainment and education program that mainly revolves around sustainability themes. The SLF is subdivided into sections according to the themes that run through the event, namely: Ludwigsstadium, Bicycle-Area, Space Invaders, Humans and the Environment, and Experience Organic Food. Each of these sections provides a sustainability-related edutainment program involving music and entertainment, and a variety of different activities linked to sports, sustainability-related mobility, climate change and conservation, charity, organic food, alternative forms of urban planning, and ways of enjoying life. The festival mainly attracts locals and visitors from the region and reaches out to a broad spectrum of visitors with different interests [36].

We selected the Munich SLF as a case-study, as the event is characterized by the most important dimensions that define a sustainability-focused event, as defined by Reference [7], being the incorporation of a sustainability policy in its organization, the objective of reducing event-related effects upon the environment, economic viability, and its focus on a sustainability-related education and entertainment program, which is meant to encourage visitors to adopt more sustainable behavior. Furthermore, this event is an interesting choice because it aims to address mainly the local community in Munich [36]. In so doing, this event is different from other green events and presents an opportunity to contribute to research. First, more insight is needed in terms of events that aim to appeal to the wider public for sustainable behavioral change [6]. This differs from other studies which have looked at green events with a complex audience mix that includes tourists [6]. Second, the location is in Germany and facilitates much needed cross-cultural comparison with the findings of Reference [6] from an Australian event. Secondly, the Munich Streetlife Festival does not carry a sustainability-related title, despite its sustainability-focus, which provides an opportunity to compare the results to those for green events which are titled as such [6].

\subsection{Questionnaire Design}

The questionnaire was divided into 4 sections covering the following aspects in accordance with the major research questions:

- Visitor profile, visitor satisfaction, and visitor expectations

- Learning success of the festival's education program for sustainability

- Pro-environmental attitude

- Pro-environmental behaviors

To encourage visitors to participate in the survey, the questionnaire, which was particularly long, was split into two halves. While the first half involved questions concerning research questions (1-2), the second half consisted of more detailed questions about attitudes and behaviors towards 
sustainability (3), which would take some time to answer. To this end, visitors received a prepaid envelope, so that they might return this questionnaire by post at a later stage.

The measures for the questionnaire are described below. The survey instrument was in part newly developed, but also included operationalizations from the literature.

\subsubsection{Visitor Profile, Visitor Satisfaction, and Visitor Expectations}

The first part of the questionnaire referred to the visitor's experience of the event, the attendees' main reasons for visiting the SLF, their overall visitor satisfaction, and personal information, such as visiting times, age, gender, education, and postcode. The items were developed in agreement with the festival organizer. While this part of the questionnaire mainly included multiple-answer questions, visitor satisfaction was measured on a five-point Likert scale, where $1=\mathrm{I}$ absolutely agree and $5=\mathrm{I}$ do not agree, at all.

\subsubsection{Learning Outcomes of the Festival}

The next section was dedicated to the learning success of the festival's education program for sustainability. More specifically, the items were taken from UNESCOs German National Plan for Action on Education for Sustainable Development [37] (e.g., "the Streetlife Festival has encouraged me ... to commit myself more strongly to the protection of the environment" or "the Streetlife Festival has made me think about the ecological and social impacts of my consumption behavior") [37]. All items in this section were measured using a five-point Likert scale, where $1=\mathrm{I}$ absolutely agree and $5=\mathrm{I}$ do not agree, at all. These measures were accounted for as self-reported measures on the learning success of the event's communication. This approach was acknowledged, for example, in Reference [6]'s study.

\subsubsection{Pro-Environmental Attitude}

Several measures were taken from the literature to assess pro-environmental attitude. First, some items were extracted from the New Environmental Paradigm (NEP Scale) [38] to measure the extent to which respondents show pro-environmental attitudes. They were: Item (1), we are approaching the limit of the number of people the earth can support; Item (2), humans have the right to modify the natural environment to suit their needs; Item (4), human ingenuity will ensure that we do NOT make the earth unlivable; Item (5), humans are severely abusing the environment; Item (13), the balance of nature is very delicate and easily upset; Item (15), if things continue on their present course, we will soon experience a major ecological catastrophe [37]. We added two further items, which were extracted from the German Environmental Awareness study [39].

To further measure the variables of the TPB, we added items to measure normative beliefs (e.g., to me it is important to protect the environment), subjective norms (e.g., people from my personal environment, such as my family, my co-workers, my professors or other students influence my decisions), and perceived behavioral control (e.g., it is easy for me to perform environmentally sustainable activities; it is my decision whether or not to perform environmentally sustainable activities) taken from Reference [40]. Two additional items were selected to take account of visitors' attitudes with particular reference to this green event (e.g., the festival is of a commercial nature; the Streetlife Festival positively contributes to the increased valuation of Leopold Street).

Furthermore, we included items which were developed by Reference [14] to measure the level of green involvement of visitors at festivals relating to green food (e.g., locally-produced food is the focus of the festival), green design, and waste management (e.g., the use of compostable and reusable dishes and flatware; we can bring our own utensils; an education program about green lives is provided; the event offers sustainability-related themes; and green materials are used for the decoration of displays and stalls). 


\subsubsection{Pro-Environmental Action}

The items selected for the measurement of pro-environmental actions were largely taken from the German Environmental Awareness study [39] (e.g., saving energy; prefer the purchase of energy-efficient equipment; saving packaging; searching for organic seals; commitment to citizenship; use resource-efficient means of transport). Furthermore, we included some items from the German travel survey [41], which indicated the extent of respondents' environmental commitment with regard to leisure and travel activities (e.g., taking part in sports; refraining from long-haul travel).

\subsection{Data Collection}

Forty-seven undergraduates from Munich University of Applied Sciences' Department of Tourism conducted a questionnaire-based survey on the weekend of 16th and 17th May 2015. The students had been intensively trained in a pre-test procedure to ensure the effectiveness of the survey. They were placed in teams of ten or twelve in the five different areas of the festival venue on Leopold Street: "Ludwigsstadium", "Bicycle-Area", "Space Invaders", "Humans and the Environment", and the "Experience Organic Food" area. Since the area "Humans and the Environment" was the most popular site, more students were situated there. The face-to-face survey was conducted during the main opening times of the event, from 4 p.m. to 11 p.m., on both days. The interviewers were instructed to sample each of the interviewed respondents by random selection. In addition, the interviewers were instructed to count the visitors at a previously determined point to assess visitor numbers in each area. Since one of the aims of the SLF was to reach out to local people, the survey was conducted in German.

In total, 471 visitors took part in the survey, with $66 \%$ responding to the second part of the questionnaire ad hoc, whilst $5 \%$ decided to return their answers by post.

\section{Results}

\subsection{Characteristics of the Sample}

The characteristics of visitors surveyed for the festival's learning outcomes are presented in Table 1 . The descriptive statistics reveal that the sample consisted of more female (55\%) than male respondents ( $45 \%$ ), and that visitors to the event were particularly young and well-educated; $48.8 \%$ were aged $21-30$ and $37 \%$ of the visitors held a university degree. The data further demonstrated that, when the attendees were approached, they had already been at the event for some time, so were well able to judge the situation and answer the questions asked.

Table 1. Sample characteristics.

\begin{tabular}{ccc}
\hline Attribute & Levels & \% Sample \\
\hline Gender & Male & 45 \\
& Female & 55 \\
\hline Age & $<20$ & 6.6 \\
& $21-30$ & 48.8 \\
& $31-40$ & 17.6 \\
& $41-50$ & 12.8 \\
& $51-60$ & 9.7 \\
& $>60$ & 4.5 \\
\hline Education & University degree & 37.0 \\
& A-levels & 34.2. \\
& O-Levels & 19.2 \\
& In training/Other & 9.6 \\
\hline Average time spent at event & Just arrived & 11.8 \\
& 15 min-1 h & 31.5 \\
& $1-2 \mathrm{~h}$ & 23.5 \\
& $2-4 \mathrm{~h}$ & 26.0 \\
& $>4 \mathrm{~h}$ & 6.6 \\
\hline
\end{tabular}




\subsection{Linking Visitor Segments to the TTM}

Similar to the procedure described in Reference [6], we identified in which of the different TTM stages the visitors found themselves when visiting the festival. We determined the positioning in the stages model by means of their ratings on five items of the NEP scales to reveal the degree of a respondent's pro-sustainable attitude, and based on the ratings of 8 items describing the level of environmental everyday behavior (see Figure 2). Attendees were classified as being in the pre-contemplation stage when they scored low, expressing their disagreement in terms of environmental attitude and never displaying environmental everyday behaviors (12.50\%). Visitors who 'sometimes' or 'never' showed environmental behaviors were placed in the hybrid stage between the pre-contemplation and action stages $(17.00 \%)$. By comparison, attendees in the pre-action stage agreed with sustainability indicators, but rarely had an environmental lifestyle (15.90\%). Visitors strongly agreeing with the NEP scales and who complied with a pro-environmental attitude by committing themselves 'often' or 'always' to sustainable practices were classified as 'action stage' respondents $(38.80 \%)$. In contrast, twelve-point-five percent of visitors classified as representatives of the 'maintenance stage' could be considered 'ecocentric' and 3.50\% of this group as 'anthropocentric'. We may derive from these results that the SLF was mainly attended by sustainability-minded visitors in the 'action' stage who firmly identified with sustainable lifestyles (38.80\%).

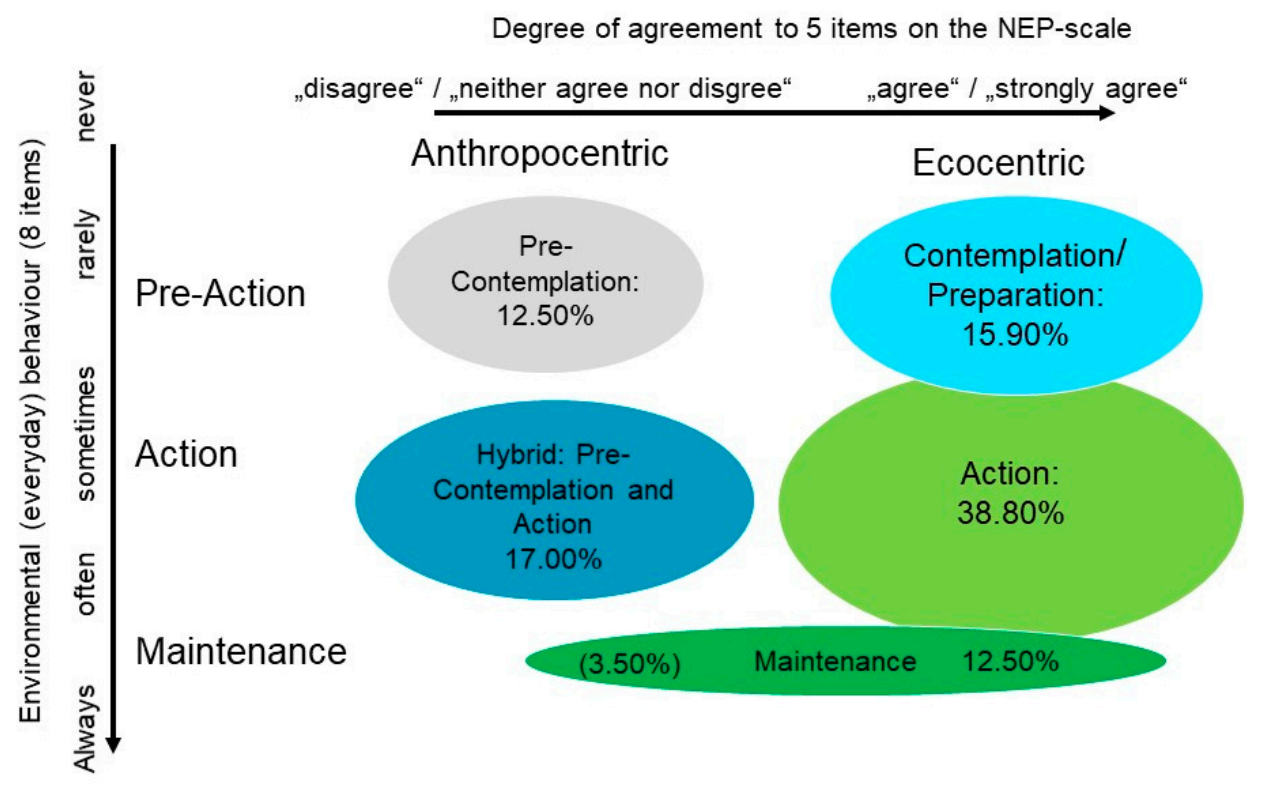

Figure 2. Linking visitor segments to the transtheoretical model (TTM).

\section{Analysis and Discussion}

Structural equation modelling (SEM) was conducted to validate and measure the constructs of the theoretical framework. To this end, we used the Iavaan package provided by the statistical software $\mathrm{R}$. The following indicators were used to assess the model fit: Chi-Square $/ \mathrm{df}=1.90$, the Comparative Fit Index (CFI) (0.807), the Root Mean Square Approximation (RMSEA) (0.058), and Standard Root Mean Square Residual (SRMR) (0.063) indicating a good fit. The latent variables of the model and their indicators, as well as the empirical results, are illustrated in Figure 3. 


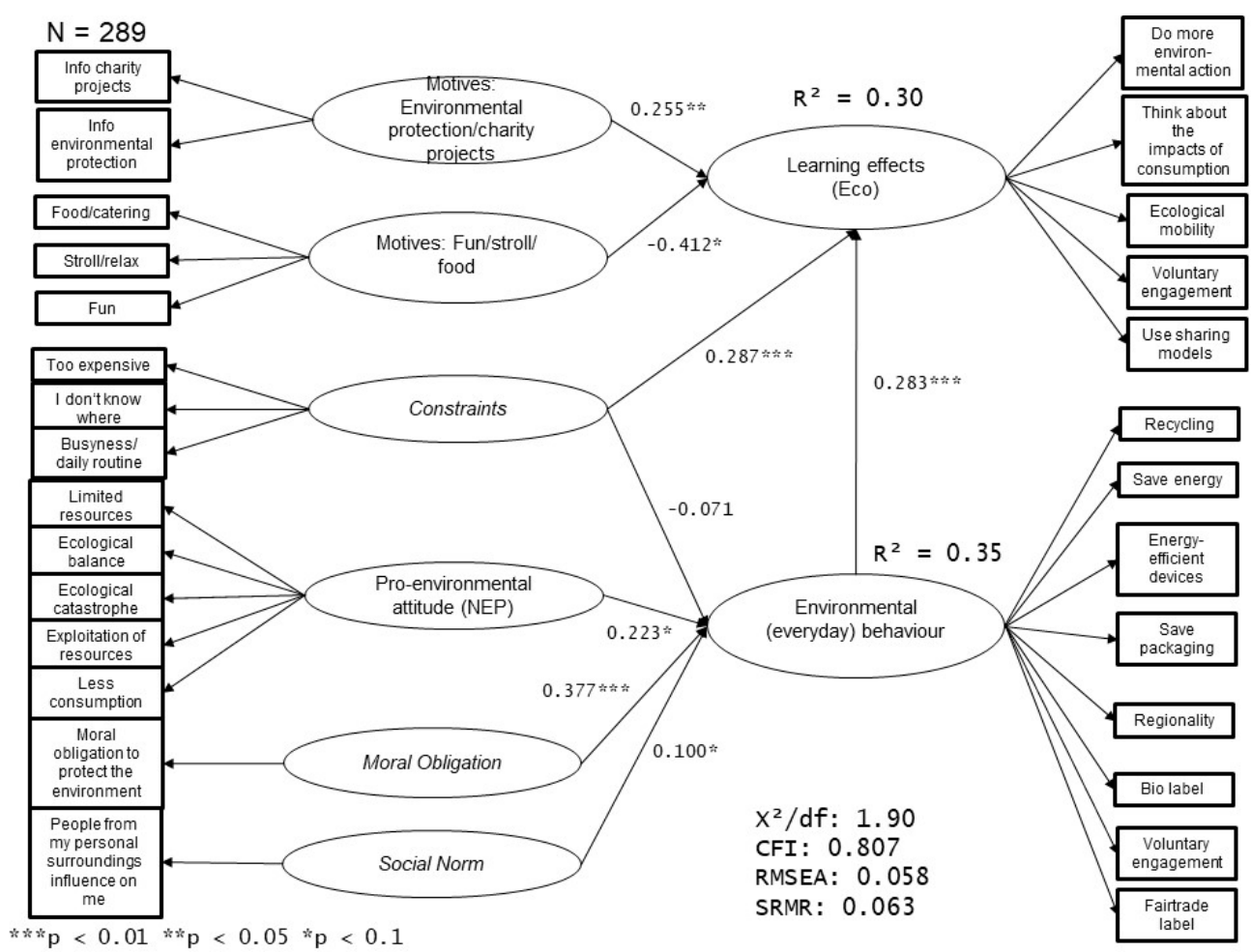

Figure 3. Structural equation modelling used to validate the theoretical framework.

To measure the latent variable and visitor motive "environmental protection/charity projects", we used items indicating whether visitors were attracted to the event, so that they could obtain information about (sustainability-related) charity projects and environmental protection. This visitor motive is positively correlated with the variable learning effects. We deduced that visitors with high scores for this motive showed increased learning outcomes from the event's sustainability program. Such learning effects suggested that these visitors showed an increased interest in engaging with pro-environmental action, thinking deeply about responsible forms of consumption, and learning about ecological forms of mobility, voluntary engagement, or the use of sharing models $(\beta=0.255$; $p<0.05)$. This supports H1. In contrast, our findings showed that the visitor motive "to have fun/stroll and enjoy the food" was negatively correlated with the variable indicating learning effects ( $\beta=-0.422$; $p<0.1$ ), giving support to $\mathrm{H} 2$. Our findings further supported the theoretical assumptions of the TPB. The statistical analysis further implied that there was a significant correlation between the learning effect of the event's sustainability program and the extent of the pro-environmental behaviors demonstrated by the interviewed visitors $(\beta=0.283 ; p<0.01$ ) (H8). Pro-environmental everyday behaviors can be measured by the extent to which event visitors indicate that they recycle, save energy, are aware of packaging, or use energy-efficient devices. Pro-environmental lifestyles also reflect more responsible consumption practices, involving the consumption of regional and sustainability-certified products and services, and of fair-trade products, or engagement in voluntary work. Furthermore, we may deduce that the level of pro-environmental worldview shown by individuals is positively related to the extent of their environmental everyday behavior. Accordingly, people who were aware that the planet's resources are limited, and that mankind's current consumption patterns harm our environment, as expressed by the NEP scales [38], also committed themselves to pro-environmental action $(\beta=0.223 ; p<0.1)(\mathrm{H} 5)$. The results further indicated that in addition to one's behavioral intentions, a subjective norm describing the influence of social peer groups $(\beta=0.100 ; p<0.1)$, and a moral norm to act pro-environmentally $(\beta=0.377 ; p<0.05)$ positively correlate with one's level of pro-environmental lifestyle (supporting Hs 6 and 7). However, in this study, constraints such as price, limited knowledge on the availability of sustainability offers, or the hectic pace of everyday 
life obviously do not prevent respondents from behaving pro-environmentally ( $\beta=-0.071 ; p>0.10$ ) $(\mathrm{H} 4)$. However, these constraints increase the amount of learning effects of the presented sustainability information among event attendees $(\beta=0.287 ; p<0.01)(\mathrm{H} 3)$. This can be explained because these individuals would like to learn more about how to overcome these barriers.

As indicated by Figure 4, our findings also reveal how different visitor segments are positioned in the various stages of the TTM model of behavioral change, which allows us to derive how far this positioning relates to visitor learning effects from the event's sustainability program. This study's results indicated that the majority of the SLF's visitors (39\%) were sustainability-minded and positioned in the "action stage" of the TTM model, because these event attendees already showed pro-sustainable behaviors in their everyday lives. The finding that green events mainly attract sustainability-conscious visitors is in line with those of other studies (e.g., References $[6,14])$. In the survey, these attendees declared that they were committed to regular recycling, saving energy and reducing waste, and to sustainable consumption practices involving the purchasing of energy-efficient or sustainability-certified products, as well as products that were locally produced or organic. Furthermore, the attendees found it important to engage in voluntary work, which they conceived to be an integral part of their sustainable lifestyle. Accordingly, these visitors were most interested in sustainability information that relates to environmental action, current consumption practices towards sustainability, the use of alternative forms of mobility, and voluntary work. The survey results were evidence that the learning outcomes of the event's sustainability communication were particularly effective with this segment of sustainability-conscious visitors. The SLF's communication program was successful in responding to this group's motivation to "learn about the environment and environmental behaviors" and to their beliefs concerning perceived behavioral control. Correspondingly, those attendees in the action stage find the SLF's communication program appealing and encouraging, motivating their sustainability behaviors to continue. Our findings were in accordance with the theoretical assumptions made by the TTM in relation to persuasive communication. Accordingly, persuasive messages were more effective for recipients who find themselves in more advanced stages of the TTM, such as those visitors in the contemplation and action stages [20]. The SLF was most effective in appealing to those visitors who already performed sustainable behaviors. Moreover, the more engaged respondents were with sustainability, the more they felt they had learned something about sustainability (the 'preaching to the converted scenario'). We can confirm this effect for sustainability communication of a green event. Our results were similar to those of Reference [6] which reported that a green event in Australia managed to reinforce extant pro-sustainable attitudes and behaviors in a group of sustainability-minded visitors. However, our evidence for this phenomenon comes from a sustainability-focused event in Germany, which is a different cultural setting. Our findings further contribute to research by investigating a green event, where the title does not identify it as such.

The survey reveals that the SLF also attracts other visitor segments. The proportions of visitors who were in the pre-contemplation $(12.50 \%)$ or contemplation stage $(15.90 \%)$, between the pre-contemplation and action stage $(17.00 \%)$, or in the maintenance stage $(3.50 \%$ and $12.50 \%)$ were very similar. In this case, the SLF's education program largely failed to appeal to visitors in the pre-contemplation stage. This group of event attendees was mainly attracted by the SLF "as an event"; that is, an opportunity for entertainment and fun, using the event as a leisure activity where they could stroll between food booths. This is reflected in the negative correlation between the motive "to stroll/have fun/food" and the extent of the learning effects. Given that the event's title does not mention a sustainability-theme, we may deduce that the communication measures were not effective in conveying the event's focus to these visitor segments. Thus, the sustainability education program was not effective in producing learning outcomes for visitors in the pre-contemplation stage. Furthermore, visitors positioned in the contemplation or preparation stage $(\beta=0.010)$ showed lower learning outcomes than individuals grouped in the pre-contemplation $(\beta=0.276)$, action $(\beta=0.352)$, or maintenance stage $(\beta=0.297)$, supporting $H 9$. The education program does not manage to reach 
these individuals who do not recognize a need to perform more sustainably in their everyday lives. Instead the event was a source of encouragement and positive feedback to those visitors who already had a sustainable lifestyle. Even though the setting was different as in the case study conducted by Reference [6], these findings were similar: The SLF fosters learning outcomes for the already "converted" audience. Hence festivals not explicitly marketed as green events, attracting a broader audience of different stages of the TTM, do not necessarily foster learning outcomes for visitors of all stages of the TTM.

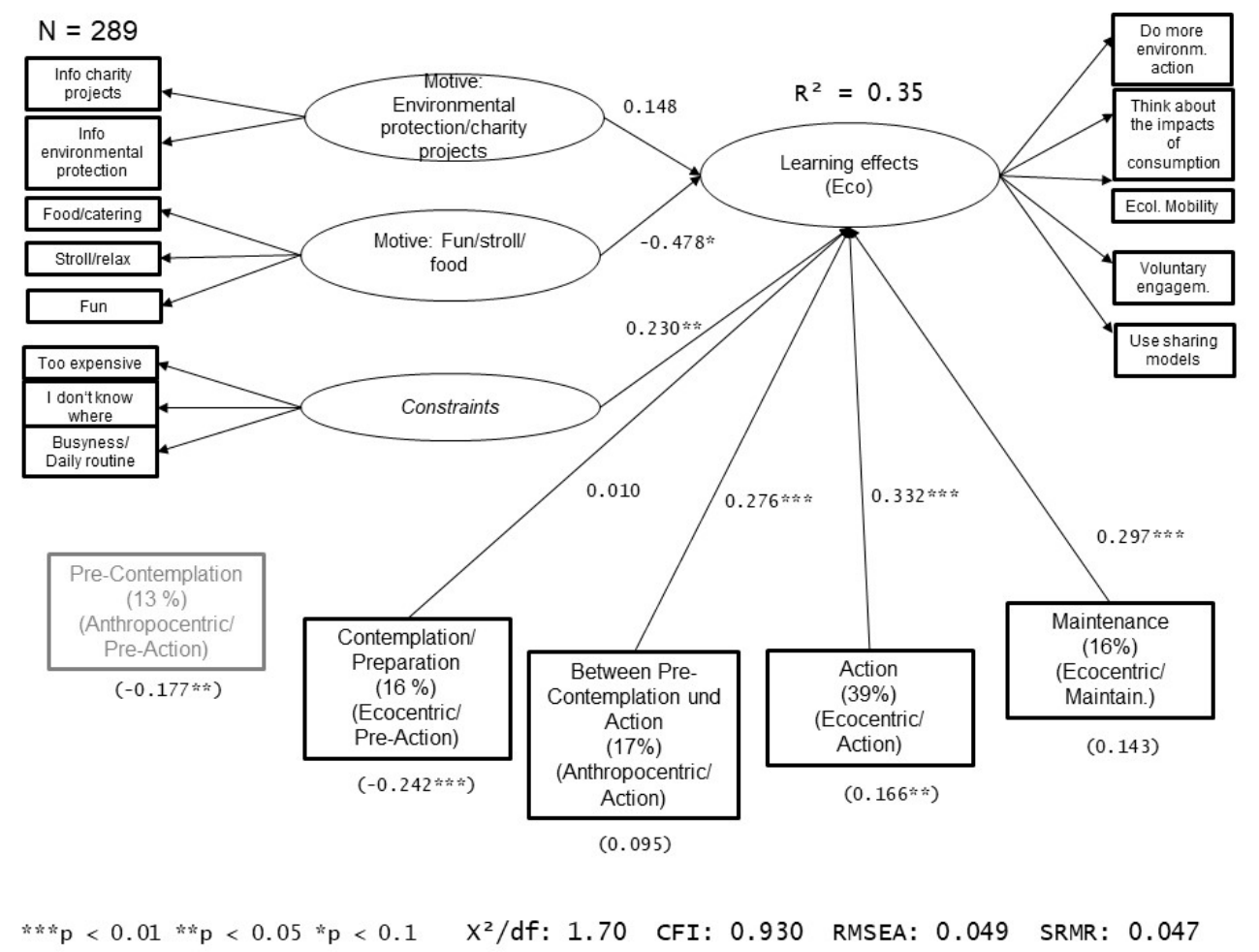

Figure 4. Linking the TTM stages with visitor learning effects for sustainability.

Comparing the results of the TPB and the TTM model, it becomes obvious that the dimensional view of the TPB reveals a linear relationship between environmental behaviors and learning outcomes. This implies that, independently from the level of environmental behavior, a learning effect can be expected. However, the categorical view of the TTM shows that this relationship is non-linear, with people in the early stages revealing nearly no learning effects, visitors in the action phase high learning effects, and when moving to the maintenance stage, learning effects decrease again. This interesting fact implies that the event might be suitable to help visitors in the action stage to stabilize in that stage or even move to the next stage.

\section{Conclusions}

As a conclusion, this study contributes to knowledge by explaining the learning outcomes of green events in motivating pro-sustainable behaviors. To this end, we investigated the effects of Munich Streetlife Festival's education for sustainable development program on different visitor segments, with varying degrees of sustainability involvement, at the event. This is the first study to attempt to explain these learning effects theoretically, whilst looking for synergies between the constructs of both the TTM [17] and the theory of behavior [18] to explain behavioral change. We collected data in a survey that we conducted at the Streetlife Festival in Munich, a big, green event that is recognized across Europe. Structural equation modelling was used to analyze the data. Subsequently, the theoretical framework was investigated in a path model involving the visitors' normative beliefs, 
subjective norms and constraints, as well as their general environmental beliefs, as represented in the constructs of the New Environmental Paradigm (NEP). The results from the data analysis supported the initially formulated research questions and allowed us to derive theoretical implications and a practitioner's contribution to knowledge.

There are several practical implications of this research from which green event planners and non-profit organizations may benefit. Our findings reveal that different visitor segments show different learning effects from the event's education for sustainability program. How best to design effective sustainability messages is an emerging research topic in tourism [26] and may pose major challenges for green event practitioners. Given that sustainability communication is most effective with target-group specific strategies [42], our results may contribute to the development of such event communications. We have identified the different stages of behavioral change among the visitors to the SLF, as a sustainability-focused event in Germany. These stages could serve as a basis for the development of more target-group specific event communications. Since we have found that this green event mainly appeals to sustainability-minded attendees, we suggest that event organizers change their communication strategy to reach out to broader audiences.

We recommend that practitioners develop stage-matched communications, which are appropriate to match visitors' current mental states when attending the SLF. To this end, we have identified the different stages of change in which the different visitor segments find themselves. We have identified that visitors in the first stages of behavioral change do not find the education programs appealing. These visitors show low attitudes towards sustainable behavioral change, so communications need to raise consciousness of sustainability-related issues and their salience amongst this audience. Since, among this visitor segment, attitudes towards adopting sustainable behaviors are weakly expressed [20], we recommend that practitioners concentrate on messages that support attitudinal change, which is the key to achieving persuasion [21] among this group of attendees. Given that these visitors' motivation is to have fun during the event, the education program for sustainability should more strongly focus on appealing to these interests. Combining sustainability-related content with forms of communication that address visitor motives for fun, leisure, and food entertainment may be more effective than behavior-related content that appeals to sustainability-minded individuals (in the action stage). We may deduce that event planners could use more emotional communication strategies for this visitor group. Other research has shown that emotional appeals are appropriate for audiences which are not sustainability-minded per se (e.g., Reference [43]), whilst informational appeals are more appealing to sustainability-conscious visitors (e.g., Reference [44]).

There are some limitations attached to this research, which have the potential to provide future directions of study. One limitation is that the survey was conducted in German. Although, from experience, most visitors were expected to come from the city and its surroundings, the language focus might have excluded some visitor groups, such as international tourists, from participating in the survey. Future surveys at the SLF may replicate and extend our research design by including other languages. As far as the event's communication strategy is concerned, the literature suggests that emotional appeal techniques are more likely to attract customers who are not primarily motivated to buy sustainably in a tourism context (e.g., Reference [44]). However, the way in which sustainability messages need to be designed in an event context to attract different visitor groups, and especially those who do not yet show any sustainability behaviors but are on the verge of considering behavioral change, has still to be researched. How to design sustainability messages that reach visitor segments which are not sustainability-minded per se is a fruitful field of research that would build on this study's results. For this purpose, we suggest the use of experimental design to test the effectiveness of different communication designs for green event sustainability communications [26].

Author Contributions: Conceptualization, C.T. and E.B.; Methodology, C.T. and E.B.; Software, E.B.; Validation, E.B.; Formal Analysis, C.T. and E.B.; Investigation, C.T. and E.B.; Resources, C.T. and E.B.; Data Curation, E.B.; Writing-Original Draft Preparation, C.T.; Writing-Review \& Editing, C.T. and E.B.; Visualization, E.B.; Supervision, C.T. and E.B.; Project Administration, C.T. and E.B.; Funding Acquisition, C.T. and E.B. 
Funding: This research received no external funding.

Conflicts of Interest: The authors declare no conflict of interest.

\section{References}

1. Getz, D. Event Management and Event Tourism; Cognizant Communication Corp.: New York, NY, USA, 1997; ISBN 9781882345465.

2. Mair, J.; Laing, J. The greening of music festivals: Motivations, barriers and outcomes. Applying the Mair and Jago model. J. Sustain. Tour. 2012, 20, 683-700. [CrossRef]

3. Getz, D.; Frisby, W. Evaluating management effectiveness in community-run festivals. J. Travel Res. 1988, 27, 22-27. [CrossRef]

4. Laing, J.; Frost, W. How green was my festival? Exploring challenges and opportunities associated with staging green events. Int. J. Hosp. Manag. 2010, 29, 261-267. [CrossRef]

5. Preuss, H. The contribution of the FIFA World Cup and the Olympic Games to Green Economy. Sustainability 2013, 5, 3581-3600. [CrossRef]

6. Mair, J.; Laing, J.H. Encouraging pro-environmental behaviour: The role of sustainability-focused events. J. Sustain. Tour. 2013, 21, 1113-1128. [CrossRef]

7. Musgrave, J.; Henderson, S. Changing audience behaviour. A pathway to sustainable event management. In The Routledge Handbook of Tourism and Sustainability; Hall, C.M., Gössling, S., Scott, D., Eds.; Routledge: London, UK, 2015; pp. 384-396, ISBN 9780415662482.

8. Duglio, S.; Beltramo, R. Estimating the Economic Impacts of a Small-Scale Sport Tourism Event: The Case of the Italo-Swiss Mountain Trail Collon Track. Sustainability 2017, 9, 343. [CrossRef]

9. Park, E.; Boo, S. An assessment of convention tourism's potential contribution to environmentally sustainable growth. J. Sustain. Tour. 2010, 18, 95-113. [CrossRef]

10. Robbins, D.; Dickinson, J.; Calver, S. Planning transport for special events: A conceptual framework and future agenda for research. Int. J. Tour. Sci. 2007, 9, 303-314. [CrossRef]

11. Mair, J.; Jago, L.K. Business Events and Climate Change: A Scoping Study; Centre for Tourism and Service Research Victoria University: Melbourne, Australia, 2009.

12. Godemann, J.; Michelsen, G. Sustainability communication-An introduction. In Sustainability Communication. Interdisciplinary Perspectives and Theoretical Foundation; Godemann, J., Michelsen, G., Eds.; Springer: Dordrecht, The Netherlands, 2011; pp. 3-11, ISBN 9789400716964.

13. Hu, H.-H.; Parsa, H.G.; Self, J. The dynamics of green restaurant patronage. Cornell Hosp. Q. 2010, 51, $344-362$. [CrossRef]

14. Wong, I.; Wan, Y.K.P.; Qi, S. Green events, value perceptions, and the role of consumer involvement in festival design and performance. J. Sustain. Tour. 2015, 23, 294-315. [CrossRef]

15. Ottman, J.A. Green Marketing: Challenges and Opportunities for the New Marketing Age; NTC Business Books: Lincolnwood, IL, USA, 1993.

16. Kim, H.; Borges, M.C.; Chon, J. Impacts of environmental values on tourism motivation: The case of FICA, Braz. Tour. Manag. 2006, 27, 957-967. [CrossRef]

17. Prochaska, J.O.; DiClemente, C.C.; Norcross, J.C. In search of how people change: Applications to addictive behaviors. Am. Psychol. 1992, 47, 1102-1114. [CrossRef] [PubMed]

18. Ajzen, I. The theory of planned behavior. Organ. Behav. Hum. Decis. Process. 1991, 50, 179-211. [CrossRef]

19. Potwarka, L.R. Exploring physical activity intention as a response to the Vancouver Olympics: An application and extension of the theory of planned behaviour. Event Manag. 2015, 19, 73-92. [CrossRef]

20. DiClemente, C.C. The transtheoretical model of intentional behaviour change. Drugs Alcohol Today 2007, 7, 29-33. [CrossRef]

21. O'Keefe, D.J. Persuasion: Theory and Practice; Sage: London, UK, 2002; ISBN 0-7619-2200-8.

22. Mair, J.; Jago, L. The development of a conceptual model of greening in the business events sector. J. Sustain. Tour. 2010, 18, 77-94. [CrossRef]

23. Kollmuss, A.; Agyeman, J. Mind the gap: Why do people act environmentally and what are the barriers to pro-environmental behavior? Environ. Educ. Res. 2002, 8, 239-260. [CrossRef]

24. Ramchadani, G.M.; Coleman, R.J. The inspirational effects of three major sport events. J. Event Festiv. Manag. 2012, 3, 257-271. [CrossRef] 
25. Chang, S.-H.; Chang, C.-W. Tie strength, green expertise, and interpersonal influences on the purchase of organic food in an emerging market. Br. Food J. 2017, 119, 284-300. [CrossRef]

26. Tölkes, C. Sustainability communication in tourism-A literature review. Tour. Manag. Persp. 2018, $27,10-21$. [CrossRef]

27. Shaw, B.R.; Radler, B.T.; Haack, J. Exploring the utility of the stages of change model to promote natural shorelines. Lake Reserv. Manag. 2011, 27, 310-320. [CrossRef]

28. Ajzen, I.; Driver, B.L. Application of the theory of planned behavior to leisure choice. J. Leis. Res. 1992, $24,207$. [CrossRef]

29. Han, H.; Hsu, L.T.J.; Sheu, C. Application of the theory of planned behavior to green hotel choice: Testing the effect of environmental friendly activities. Tour. Manag. 2010, 31, 325-334. [CrossRef]

30. Lam, T.; Hsu, C.H. Predicting behavioral intention of choosing a travel destination. Tour. Manag. 2006, $27,589-599$. [CrossRef]

31. Shen, S.; Schüttemeyer, A.; Braun, B. Visitor's intention to visit world cultural heritage sites: An empirical study of Suzhou, China. J. Travel Tour. Mark. 2009, 26, 722-734. [CrossRef]

32. Sparks, B. Planning a wine tourism vacation? Factors that help to predict tourist behavioural intentions. Tour. Manag. 2007, 28, 1180-1192. [CrossRef]

33. Horng, J.; Su, C.; So, S. Segmenting food festival visitors: Applying the theory of planned behavior and lifestyle. J. Conv. Event Tour. 2013, 193-216. [CrossRef]

34. Chib, A.; Chiew, H.J.; Kumar, C.; Lim, G.C.; Ale, K. [Minus]plastic: Influencing pro-environmental attitudes among Singaporean youth. Environ. Edu. Res. 2009, 15, 679-696. [CrossRef]

35. Jackson, T. Motivating Sustainable Consumption. A Review on Evidence of Consumer Behaviour and Behaviour Change; A Report to the Sustainable Development Research Network; Centre for Environmental Strategy, University of Surrey: Guildford, UK, 2005.

36. Greencity. Available online: http:/ / www.streetlife-festival.de/ (accessed on 16 August 2018).

37. Bundesministerium für Bildung und Forschung. Nationaler Aktionsplan für Deutschland. UN-Dekade Bildung für Nachhaltige Entwicklung; Bundesministerium für Bildung und Forschung: Berlin, Germany, 2005.

38. Dunlap, R.E.; Van Liere, K.D.; Mertig, A.G.; Jones, R.E. New trends in measuring environmental attitudes: Measuring endorsement of the new ecological paradigm: A revised NEP scale. J. Soc. Issues 2000, 56, 425-442. [CrossRef]

39. Bundesministerium für Umwelt, Naturschutz, Bau, und Reaktorsicherheit. Umweltbewusstsein in Deutschland. Ergebnisse Einer Repräsentativen Bevölkerungsumfrage; Bundesministerium für Umwelt, Naturschutz, Bau, und Reaktorsicherheit: Berlin, Germany, 2015.

40. Swaim, J.A.; Maloni, M.; Napshin, S.; Henley, A. Influences on student intention and behavior toward environmental sustainability. J. Bus. Ethics 2014, 124, 465-484. [CrossRef]

41. Forschungsgemeinschaft Urlaub und Reisen e.V. Nachfrage für Nachhaltigen Tourismus im Rahmen der Reiseanalyse; Forschungsgemeinschaft Urlaub und Reisen e.V: Kiel, Germany, 2014.

42. Dolnicar, S.; Leisch, F. Selective marketing for environmentally sustainable tourism. Tour. Manag. 2008, 29, 672-680. [CrossRef]

43. Wehrli, R.; Priskin, J.; Demarmels, S.; Schaffner, D.; Schwarz, J.; Truniger, F.; Stettler, J. How to communicate sustainable tourism products to customers: Results from a choice experiment. Curr. Issues Tour. 2017, 20, 1375-1394. [CrossRef]

44. Wehrli, R.; Priskin, J.; Schaffner, D.; Schwarz, J.; Stettler, J. Do sustainability experienced travellers prefer a more rational communication of the sustainability of a tourism product? WIT Trans. Ecol. Environ. 2014, 187. [CrossRef]

(C) 2018 by the authors. Licensee MDPI, Basel, Switzerland. This article is an open access article distributed under the terms and conditions of the Creative Commons Attribution (CC BY) license (http:/ / creativecommons.org/licenses/by/4.0/). 